\title{
Molecular Aggregations and Induction of Anisotropy by Light in Azodyes
}

\author{
Tariel Ebralidze $e^{1, ~ *, ~ N a d i a ~ E b r a l i d z e ~}{ }^{1}$, Giorgi Mumladze ${ }^{2}$ \\ ${ }^{1}$ Department of Coherent Optics and Electronics, Vladimer Chavchanidze Institute of Cybernetics of the Georgian Technical University, \\ Tbilisi, Georgia \\ ${ }^{2}$ Department of Computer Engineering Elements and Nanomaterials, Vladimer Chavchanidze Institute of Cybernetics of the Georgian \\ Technical University, Tbilisi, Georgia
}

Email address:

tarebra@yahoo.com (Tariel Ebralidze),g.mumladze@gtu.ge (G. Mumladze)

\section{To cite this article:}

Tariel Ebralidze, Nadia Ebralidze, Giorgi Mumladze. Molecular Aggregations and Induction of Anisotropy by Light in Azodyes. Optics. Vol. 4, No. 2, 2015, pp. 13-16. doi: 10.11648/j.optics.20150402.11

\begin{abstract}
The anisotropy induction by light in self-induced molecular aggregations ensemble of azodyes has been studied. In the dynamic regime of anisotropy photoinduction the video-microscopy investigations of the film having photoinduced anisotropy in the crossed polarizers have been conducted. It is shown that image formation herein can be carried out in the way of light modulation of the granular anisotropy integral area of the film. According to an active light exposition, both the concentration and sizes of molecular aggregates having photoinduced anisotropy are being modulated.
\end{abstract}

Keywords: Anisotropy Photoinduction, Molecular Aggregations

\section{Introduction}

Gelatin or other gel films dyed by azodyes are the subject of a keen interest because of their possible application in the information optical recording, non-linear optics, holography etc, which is based on the phenomena of the optical anisotropy photoinduction [1].

It is known that film transparency with photoinducted anisotropy is the function of active light exposition in the crossed polarizers. Thus, when we imagine a film with photoinducted anisotropy as a monocrystal, it is considered that the abovementioned transparency modulation takes place based on the modulation of birefringence value of the film. However, besides, in our opinion, image formation in film during the anisotropy photoinduction can be carried out in the other way, in particular, anisotropy can be induced by "grain" distribution and their concentration would be modulated by light exposition [2].

In existing views, photoinduction of optical anisotropy in azodyes is a result of cis-trans isomerisation process [3, 4]. To obtain a clear effect, it is necessary that the dye concentration in the solution is as high as possible. However, the high amount of dye concentration in solutions unconditionally leads us to self-induction of the dye molecules' aggregates in solid films, or leads to such state when aggregates are induced by light stimulation [2, 5-11].

In $[8,10]$, in the gelatin film dyed by mixture of Chrisophenine and Acridine Yellow saturated water solutions, self induction of anisotropic micro particles ensemble has been realized; and there has been carried out a control of optical axes orientation and anisotropy integral area in this ensemble.

In the work [11], in the polyvinyl film saturated by dye "Mordant Pure Yellow" (MPY) anisotropy photoinduction in the "granulouos" form has been observed; and the obtained anisotropy integral area through the active light exposition was modulated; there weren't aggregates at the beginning and we had a total isotropic starting picture.

Here, in distinction to [11], we present the results of investigation, according to which the anisotropy photoinduction in the polyvinyl film saturated by "MPY" [12] in self-formed dye molecular aggregations is realized. These isotropic self-formed aggregates appeared in the film preparation process.

\section{The Experiment and Results}

The experiment was carried out for the polyvinyl film dyed by "Mordant Pure Yellow" (MPY) with thickness of approximately $100 \mathrm{mkm}$.

The absorption spectrum has a form presented on Fig. 1(a). 
The structural formula of the azodye "Mordant Pure Yellow" (MPY) is presented on the Fig. 2(b).

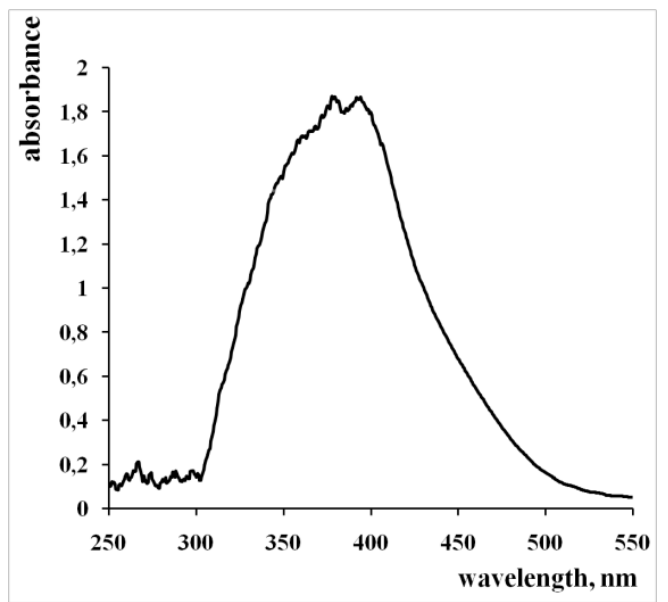

Fig. 1(a). The absorption spectrum of the experimental film (polyvinyl alcohol film dyed by dye "Mordant Pure Yellow" (MPY).

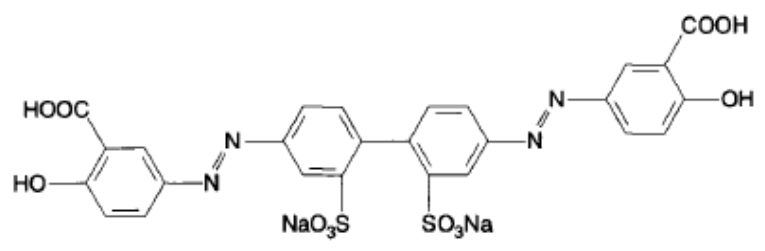

Fig. 1(b). Formula of the dye "Mordant Pure Yellow" (MPY).

The anisotropy photoinduction in the film was conducted by linearly polarized light of the $100 \mathrm{w} / 2 \mathrm{Hg}$-lamp from a narrow spectral band containing $440 \mathrm{~nm}$ wavelength.

Observing of the film with photoinduced anisotropy was conducted in crossed polarizers. There was a 45 degrees angle between the optical axes of polarizers (analyzer-polarizer) and polarization vector of active light.

In the dynamic regime of anisotropy induction, series of anisotropic area images obtained in the crossed polarizers have been recorded by the $5 \mathrm{Mpx}$ microscopic ocular camera. 60 images have been shot (with $2 \mathrm{sec}$. time interval between them).

Series of shot images conditionally in 4 parts have been divided. Then 4 images from all the series have been selected: first, Fig. 2(a) - from the 1st part; next, Fig. 2(b) and (c) and (d) - from the $3^{\text {rd }}$ and 4 th parts of the pictures' series accordingly. Here, pictures' numeration matches with the increasing of exposition time. Here, the same areas of figures by the rectangular frame are outlined.

If we pay our attention to the area outlined by frame in the Fig. 2(a), we can notice that the number of clearly visible granular aggregates is much smaller than in the Fig. 2(b). But in the Fig 2(c) the aggregates in the same frame are located very densely. What concerns to the Fig. 2(d), we observe almost continuous location of aggregates in the micro areas.

We've taken these 4 pictures from 4 categories based on the defined visual effect only. Every single picture represents typical situation in its category. There is no specified time interval between the 4 presented pictures.

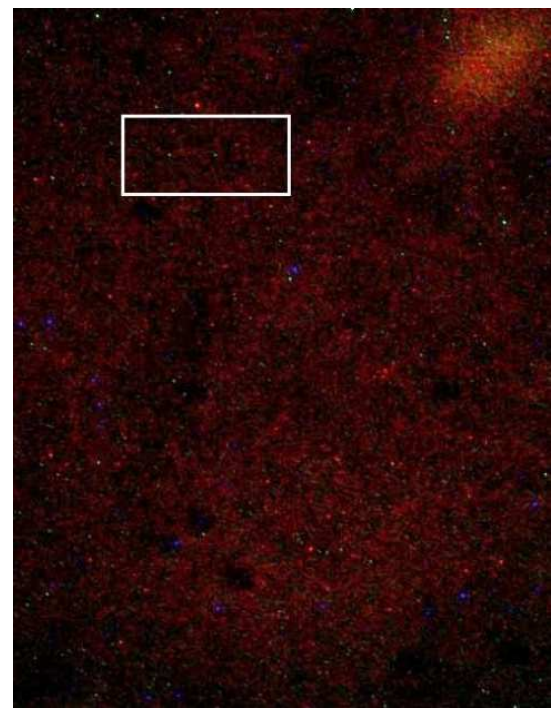

(a)

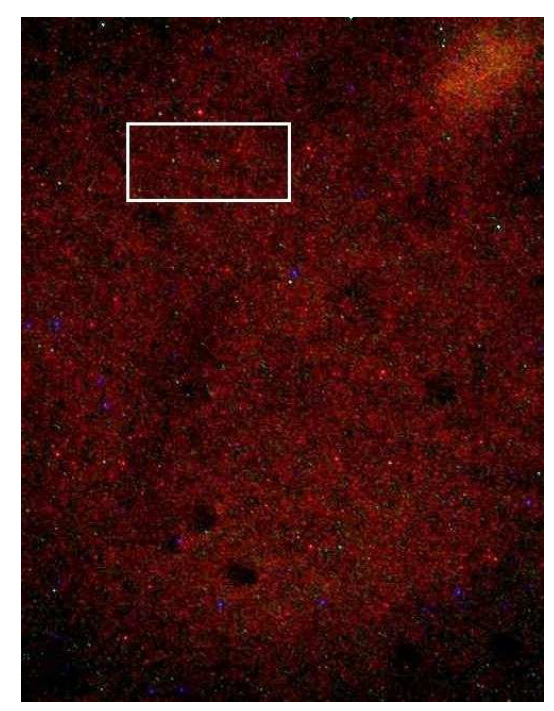

(b)

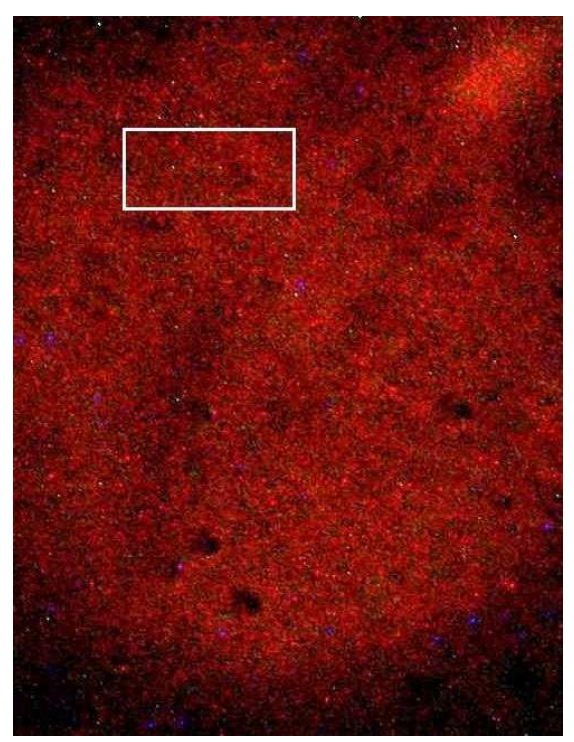

(c) 


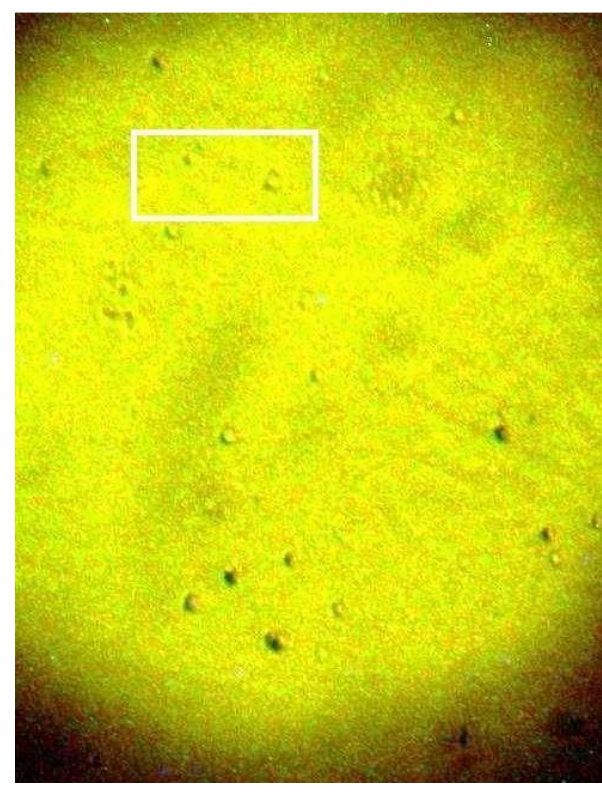

(d)

Fig. $2(\boldsymbol{a}, \boldsymbol{b}, \boldsymbol{c}, \boldsymbol{d})$. images of film with photoinduction anisotropy in the crossed polarizers.

\section{Analysis of the Experimental Results}

As we can see, under the influence of a linear polarized active light in the film, optical anisotropy arises. Transmission of the film in the crossed polarizers increases according to an active light exposition. Anisotropy photoinduction is realized in the single molecular aggregates.

Although the molecular aggregates were the object of approximately same light intensity, in aggregates we obtain the effects with different values. For example, the Fig.2c shows clearly that light brightness, passed into aggregates isn't same in all places.

We assume it's a reason is that we have the light influence on the vector, not scalar environment. Here, reaction of material on the action of the linear polarized active light is not defined by energy only. It depends on the degree of orientation-disorientation in the molecular aggregates as well. The abovementioned reactions in aggregates are different, because, in general, this degree in spontaneously induced aggregates is not similar.

At the beginning, anisotropy is realized in the single parts of molecular aggregates - in "centers", whose concentration and sizes increase according to active light exposition. This causes increasing of aggregates alight "centers" areas and rising of their visibility accordingly.

Thus, according to a light exposition, the integral area of anisotropy micro parts in a film increases. It is easy to make sure of it if we compare the microstructures of the pictures' group presented here, which have been shot early and later in time.

It is necessary to mark that all the images presented here are obtained by the auto correction option. This option gave us the difference in their colors.

\section{Conclusion}

Thus, it has been shown for the polyvinyl alcohol film saturated by azodye "MPY" that the anisotropy induction can be obtained by anisotropy photoinduction in dye molecular aggregations, which are object of self-induction during the film preparation process. According to the anisotropy exciter light exposition, integral area of photoinduced anisotropy is modulated in aggregates.

\section{Acknowledgment}

Authors express gratitude for the analysis of the obtained results to Dr. Andro Chanishvili.

\section{References}

[1] T. Kondo, Z. Wiss Photogr. Photophys. Photochem. (in German) 31,153 (1932).

[2] T. D. Ebralidze and A. N. Mumladze, "Light-induced anisotropy in azo-dye-colored materials," Applied Optics, vol. 29, no. 4, pp. 446-447, 1990.

[3] A. M. Makushenko, B. S. Neporent, B. S. Neporent, and O. V. Stolbova, "Reverssible orientational photodichroism and photoisomerization of aromatic azo compounds. I," Optics and Spectroscopy (USSR), vol. 31, pp. 557-564, 1971.

[4] F. L. Labarthet, S. Freiberg, C. Pellerin, M. Pézolet, A. Natansohn, and P. Rochon, "Spectroscopic and optical characterization of a series of azobenzene-containing side-chain liquid crystalline polymers," Macromolecules, vol. 33, no. 18, pp. 6815-6823, 2000. View at Publisher View at Google Scholar View at Scopus

[5] T. D. Ebralidze, N. A. Ebralidze, A. N. Mumladze, "Photoinduction of anisotropic grains in organic compounds", Applied Optics, 37, 6161-6163, (1998)

[6] D. Voloschenko and O. D. Lavrentovich, "Light-induced director-controlled microassembly of dye molecules from a liquid crystal matrix," Journal of Applied Physics, vol. 86, no. 9, pp. 4843-4846, 1999. View at Scopus

[7] B. J. Kim, S. Y. Park, and D. H. Choi, "Effect of molecular aggregation on the photo-induced anisotropy in amorphous polymethacrylate bearing an aminonitroazobenzene moiety," Bulletin of the Korean Chemical Society, vol. 22, no. 3, pp. 271-275, 2001. View at Scopus

[8] T. D. Ebralidze, N. A. Ebralidze, G. A. Mumladze, and E. S. Kitsmarishvili, "Light-controlled mass formation of aggregates of molecules in organic compounds," Chinese Optics Letters, vol. 7, no. 9, pp. 823-825, 2009. View at Publisher View at Google Scholar View at Scopus

[9] A. Priimagi, A. Shevchenko, M. Kaivola, F. J. Rodriguez, M. Kauranen, and P. Rochon, "High and stable photoinduced anisotropy in guest-host polymer mediated by chromophore aggregation," Optics Letters, vol. 35, no. 11, pp. 1813-1815, 2010. View at Publisher View at Google Scholar View at Scopus

[10] T. D. Ebralidze, N. A. Ebralidze, and G. A. Mumladze, "Anisotropy Photoinduction during the Mass Associations of Dye Molecules in Gelatin Films", Journal of Materials, Volume 2013 (2013), Article ID 507938, 3 pages 
[11] Tariel Ebralidze, Nadia Ebralidze, Giorgi Mumladze. "Molecular Aggregations and Anisotropy Photoinduction in Organic Compounds", Optics. Vol. 3, No. 4, 2014, pp. 33-36. doi: $10.11648 /$ j.optics.20140304.12

[12] M. Ivanov, L. Nikolova, T. Todorov, "Photoinduced dichroism and birefringence in films of Mordant Pure Yellow/poly(vinil alcohol): simultaneous real-time investigations at two wavelengths", Optical and Quantum Electronics, November 1994, vol.26, Issue 11, pp.1013-1018, doi: 10.1007/BF00305001. 